\title{
$\underline{\text { Islands of vulnerability and resilience: Manufactured stereotypes? }}$
}

\begin{abstract}
This paper interrogates the aspects of islandness labelled 'vulnerability' and 'resilience' through analysing the concepts' definitions from a development perspective. The investigation is conducted through the lens of four assumed islandness aspects: boundedness, smallness, isolation, and littorality. Discussion examines how and why core concepts of vulnerability and resilience have emerged from island studies, demonstrating how these two aspects of islandness are socially and culturally constructed, can influence development approaches taken, and are enhanced by island geographies. Drawing on insights from island geographies around the world, while comparing island and nonisland perspectives, evidences how manufactured islands of vulnerability and resilience can slant the discourse and reinforce stereotypes, especially in terms of the four assumed aspects of islandness. Island geographies in their diversity teach that vulnerability and resilience, being neither opposites nor independent or objective variables, are most supportive of island development endeavours when accepted as being subjective, contextualised, and nuanced. The lessons yield advice on ensuring that development contexts for vulnerability and resilience are widened and deepened, drawing strength rather than constraints from the four assumed aspects of islandness. Within boundedness, smallness, isolation, and littorality, the two aspects vulnerability and resilience can be empowering and disempowering for development.
\end{abstract}

\section{Keywords}

development, islandness, island studies

\section{Islandness in development}

Island geographies - islands, archipelagos, their communities, and their peoples-infuse much research, policy, and practice for development-related work, often framed through 'vulnerability' and 'resilience' (Encontre 1999; Lewis 1999; UN 2014). In development contexts across multiple schools of thought from research, policy, and practice (see overviews by Alexander 2013; Gaillard 2010; and Lewis 2009), vulnerability and resilience can be broadly interpreted as, respectively, undermining and building communities and livelihoods which are safe and healthy, hence covering sectors and services such as food, water, education, social services, health, jobs, economies, transport, and energy. Interlinked development topics contributing to vulnerability and resilience discourses for island geographies include ocean governance and the blue economy (Silver et al. 2015); climate change (IPCC 2013-2014); migration and remittances (Oberst and McElroy 2007); and disaster risk reduction (UNISDR 2017).

Island geographies range from Arctic hamlets such as Grise Fiord, Nunavut to tropical countries with millions of residents such as Singapore (the debate regarding how off-island land transportation links might affect islandness is addressed later). Some island geographies are small pieces of land far from other habitations, such as Tristan da Cunha in the South Atlantic. Others belong to megacities, such as Manhattan. Irrespective of this variety, development work frequently assumes that island peoples and places have inherent aspects which make them vulnerable, thereby requiring development efforts (Pelling and Uitto 2001; UN 2014).

Four main aspects of island geographies, or of islandness, tend to be highlighted, discussed, deconstructed, and critiqued with respect to development (Baldacchino 2018; Lewis 2009; Grydehøj 2017). First, being bordered or bounded with clearly demarcated land-based spatial limits. Second, being small in terms of land area, population, resources, and livelihood opportunities. Third, distance, marginalisation, isolation, or separation from other land areas, peoples, and communities. Fourth, 
littorality, referring to land-water interactions, coastal zones, and intersections of archipelagos and aquapelagos (Hayward 2012). Assumptions of these four aspects' presence for island geographies and how they induce the further aspect of island vulnerability in a development context is made by, amongst others:

- social science, e.g. Hong Kong's outer islands, lacking public transport other than ferries, are underdeveloped (Leung et al. 2017) because island geographies are bounded, small, marginalised, and distanced;

- natural science, e.g. island biodiversity which connects to development through mechanisms such as the Convention on Biological Diversity and Sustainable Development Goals 14 and 15, while linking to all four assumed aspects of islandness;

- sustainability policy, e.g. justifying the small island developing states (SIDS) grouping (UN 2014) and the blue economy (Silver et al. 2015) by focusing on all four assumed aspects of islandness;

- literature, e.g. Daniel Defoe's 1719 novel Robinson Crusoe, and popular entertainment, e.g. the movie The Rock (1996) about a hostage situation on Alcatraz, both highlighting the islandness aspects of being bordered, small, and isolated.

Two development counterdiscourses emerge, challenging the idea that the four islandness aspects cause island vulnerability. First, disputed views of island geographies, demonstrating that the assumed four aspects are stereotypes which sometimes characterise the entire island geography and which are sometimes present sparingly. For instance, in Copenhagen's South Harbour, new apartment complexes are built on artificial islands separated by narrow water channels creating small pieces of land surrounded by water, but displaying few other aspects of islandness. Contrasting views of islandness based on counterexamples are raised in the literature (Baldacchino 2018; Campbell 2009; Grydehøj 2015) and are also addressed in other papers in this issue.

The second counterdiscourse is that resilience is the solution to vulnerability. This story-heavily critiqued (Alexander 2013; Reid 2012) — is that resilience is the opposite of vulnerability and represents abilities to deal with adversity while remaining fundamentally unchanged, although sometimes the contradictory expectation for resilience is remaining fundamentally unchanged by changing due to adversity. Resilience for islands is said to exist due to the four assumed islandness aspects and despite them. This form of vulnerability discourse with the resilience counterdiscourse is assumptive about aspects of islandness, does not acknowledge the origins and depth of vulnerability and resilience ideas from disciplines other than ecology, does not fully include non-island contributions and insights, and can be counterproductive for island development endeavours.

To contribute to ongoing geography debates, this paper explores the islandness aspects of vulnerability and resilience through the lens of the four assumed islandness aspects of boundedness, smallness, isolation, and littorality. This examination demonstrates how to shift from island geographies being assumed to be vulnerable and resilient towards vulnerability and resilience being islands unto themselves.

\section{Vulnerability and resilience as aspects of islandness}

While recognising the debates surrounding the meanings of 'vulnerability' and 'resilience' for development challenges (Alexander 2013; Gaillard 2010; Lewis 1999), both island and non-island geographies display characteristics of each (Campbell 2009; Lewis 2009). Disaster-related work in the context of development has long emphasised the contextuality of vulnerability and resilience, accepting them as social and cultural constructions (Glantz 1976; Hewitt 1983; Lewis 1999; Wisner 1993).

Yet many languages, especially indigenous island languages such as Inuktitut (not exclusive to islands) and Tongan, do not have words for 'vulnerability' or 'resilience', plus the cultural constructs 
are hard to explain (based on explanations from native speakers of these languages). Consequently, vulnerability and resilience can frequently mean whatever contextual or disciplinary definitions they are assigned, making them siloed by language, field of study, and application. This point does not deny that materiality of damage, harm, and pain occurs or that mechanisms exist for dealing with it and for preventing it. Instead, it indicates that 'vulnerability' is not necessarily entirely embraced by damage, harm, and pain nor 'resilience' by dealing with or preventing it. Interpreting islands of vulnerability and resilience within the four aspects of islandness of boundedness, smallness, isolation, and littorality must be conducted within this diffuse understanding of vulnerability and resilience.

Borders delineate locations of responsibility. Since the jurisdiction might be clear, so might be responsibility for planning and focusing development efforts and thereby supporting resilience. Borderlands, though, are frequently distant from decision-making centres (with exceptions of capital cities adjacent to international borders, e.g. Asunción and Lomé) leading to marginalisation which sometimes supports vulnerability (Wachtendorf 2000).

Smallness and isolation potentially lead to vulnerability due to lack of local resources and difficulties in delivering external resources. This concern is frequently raised in policy venues to highlight island needs (e.g. UN 2014). Yet if a community recognises this situation and realises that they must succeed with what they have, then resilience might be built by smallness and isolation spurring local action. Examples of island communities which reduced disaster casualties by implementing their own local warning system are Tikopia and Anuta in the Solomon Islands for a 2002 cyclone (Treadaway 2007) and Simeulue, Indonesia for a 2004 earthquake-induced tsunami (Gaillard et al. 2008).

Finally, littorality brings opportunities through resources for fishing, tourism, and trade (Silver et al. 2015). These opportunities provide resilience via livelihoods, income, and potentially skills and diversity. If skills are not developed or if diversity is not supported, then reliance on a single industry, or investment into infrastructure without local returns, can breed vulnerability. This situation is amply demonstrated for the island tourism industry alongside solutions for using a tourism focus to overcome island vulnerability (Su et al. 2017).

Island geographies further demonstrate how defining the terms 'vulnerability' and 'resilience', followed by using them as labels, can construct these aspects for and confer them on the very contexts in which they are described. If people and communities are labelled as being vulnerable, they could simply accept it, expecting external assistance, direction, resources, and leadership to address development issues. The foisting of the 'vulnerable' label can be demoralising, disincentivising action as per the suggestion from Pacific islanders of the 'handout mentality' (Tuiloma-Palesoo 2004) displayed through waiting for presumed post-disaster aid so little reason exists to help oneself. Thus, resilience opportunities are lost due to the 'vulnerability' label.

Meanwhile, labelling people and communities as 'resilient' is used to avoid providing external support. Reid (2012 and see also Pugh 2014) argues that terming people 'resilient' is used to reduce government roles in development work, as it supports the neoliberal attitude that people can and should take care of themselves. Resilience thus becomes full self-reliance meaning that requesting external assistance is discouraged. Thus, vulnerability can be created due to the 'resilience' label.

Island peoples and communities, though, are not passive agents waiting for labels and accepting whatever they are called. Many residents of Troms $\varnothing$ island, Norway and South Island, New Zealand are comparatively well-educated, well-resourced, and with opportunities to speak up for development action. With limited worry of retribution, they can vote, stand for office, publicise their views, and convince others. Conversely, since Maldives gained independence in 1965, it has had only one President who was ostensibly democratically elected (Mohamed Nasheed from 2008-2012) and he also severely restricted freedoms and was involved in governance abuses. Maldivians have always 
had limited opportunity to set their country's own development direction through government. They have nonetheless created and adopted ample opportunities outside of government, through emigrating to the capital or outside the country for education and jobs-overcoming boundedness-, smallness-, and isolation-induced vulnerability - as well as setting up and running small (inevitably small) businesses, typically based on littorality, to support their own resilience.

All these choices affect vulnerability and resilience, with the balance often dictated by the exact context and mode of implementation. Maldives used to separate tourist resort islands from islands where Maldivians lived, making use of islands' littorality and boundedness. Now, Maldivians are permitted to operate tourist accommodation on islands where people live. Giving opportunities for self-run livelihoods can generate resilience by stimulating development activity and encouraging collaboratively initiated and managed investments in one's own community. It can also generate vulnerability through reliance on external forces such as airfares and tourists' whims as well as through internal mistakes such as poor business strategy and selfishness to maximise one's personal profit.

Kangaroo Island in Australia typically had two ways off-island: a turboprop flight to Adelaide or a ro-ro ferry to Cape Jervis with frequent winter cancellations due to storms. In late 2017, to overcome boundedness, smallness, and isolation, an extended runway opened, permitting another airline company to fly from Adelaide and, during peak season, Melbourne (also with turboprops). The investment and initial boost in visitors created jobs and income yielding dimensions of resilience if accepted as being augmented financial and livelihood choices and opportunities, at least in the short term, but no alteration occurs in the jobs and income being highly vulnerable to airline company mandates of prioritising profit. The ferry company is also for-profit and often gives less than an hour's notice that they are operating or cancelling a ferry, a situation which locals have grudgingly learned to accept, but which brings significant reputational risk for the tourism industry.

Analogies occur in non-island locations, with decaying Olympic legacies being prominent (e.g. Albertville in 1992; Terret 2008), but island geographies bring these vulnerabilities and resiliences to the forefront. The comparative smallness and isolation aspects of islandness demonstrate how a small change can make a big difference. A few more or slightly fewer flights a week into Kangaroo Island substantially alters the road traffic levels and tourism service demands. Locations without restricted transport or with larger scales of movement would require a much bigger change to make-or-break livelihoods. While low-cost airline companies across continental Europe were heralded as revitalising poorer areas around regional airports, longer-term evidence is mixed in terms of increased revenue and overall economic impact (Castillo-Manzano et al. 2012; Lei and Papatheodorou 2010), so it is not as clear-cut as some island examples.

As well, the local investment demanded by the low-cost airline companies could have been used for alternative ways of drawing in visitors, whereas Kangaroo Island has only two alternatives for increasing tourist numbers: more flights or more ferry crossings. In fact, despite the unwelcome infrastructure legacy of the 2014 FIFA World Cup and the 2016 Summer Olympics, Rio de Janeiro remains a prime tourist destination due to alternatives including beaches, Carnival, parks, and performances. Conversely, literature mainstays are island depopulation due to few opportunities (e.g. Fetlar, Sheltand from Grydehøj 2008) and attempts at island revitalisation focused on re-branding a single industry (e.g. Malta's beach tourism from Dodds 2008).

When assumed aspects of islandness are present, vulnerabilities and resiliences as aspects of islandness tend to be enhanced by the islandness. Islanders can take direction from the four assumed aspects of islandness to develop what they need and seek with respect to vulnerability (presumably reducing it) and resilience (presumably increasing it). Without neglecting wider contexts, including ethical and legal obligations, much can and should be done on the islanders' own terms. Rather than 
outsiders determining which actions islanders should take regarding vulnerability and resilience, outsiders should enable islanders to act for themselves on the basis of aspects of islandness, not despite them.

\section{Manufactured islands of vulnerability and resilience?}

Presuming aspects of islandness in order to interpret islands as being vulnerable and resilient mechanises the reality of what many islanders know and live. The stereotypes have plenty of truth in them for some islands, but limited scope for others. Vulnerabilities and resiliences are inevitably multidimensional and multifactorial, hence islands are not merely either vulnerable or resilience, but by various definitions, all peoples, places, and communities have aspects of vulnerability and resilience to different degrees and in different ways.

Additionally, the assumed aspects of islandness frequently apply to (and are frequently unsupported stereotypes for) what would ostensibly be non-island geographies. Despite lacking littorality, many mountain villages and landlocked countries such as Lesotho and the Vatican are seen as islands because they are small in land area and are delineated and isolated jurisdictionally, however artificially and arbitrarily, from the areas around them. Belize and Guyana are often seen to be Anglophone islands within Latin America. They are traditionally much more connected to the political structures from the Anglophone Caribbean, such as the Caribbean Community (CARICOM), than to their neighbouring countries. This political situation leads to some isolation from spatially nearby jurisdictions and, with each country having coastlines and most of its infrastructure and population near the coast, a degree of littorality.

When examined through the lens of islandness aspects, these mainland areas could display more assumed islandness than islands such as Manhattan within New York City (Anderson 2016) and Haizhu within Guangzhou (Su 2017). Nevertheless, assumed aspects of islandness are not entirely absent from these island geographies. After the terrorist attacks of 11 September 2001, evacuating Manhattan proved difficult, so a self-organised boat flotilla ferried people off the island followed by boarding self-organised busses at the landing points (Kendra and Wachtendorf 2016). Was Manhattan vulnerable because of the evacuation difficulties, resilient because locals found a solution (while using their boats to support the emergency services), or both (see also Joseph 2013)? How was it similar to or different from the WWII evacuation from the mainland location of Dunkirk?

Aspects of islandness are therefore perhaps more aspects of geographies, covering places (physical locations which can be delineated by political, geomorphological, or other boundaries; hence they are bounded somehow) and non-place-based communities (which share characteristics, even if not in the same or bordering locales). Despite both legal (UNCLOS 1982) and academic (Hay 2006) efforts to define an 'island', the term might often apply to a concept or an intuited expression rather than to place-based geography of the typical 'small piece of land surrounded by water'. Even this paper's contrast of 'island' and 'non-island' is problematic because 'non-island' is defined via exclusionby what it is not - rather than accepting it in its own right as with 'mainland'. The island-mainland comparison could be expressed more as a continuum than as a dichotomy, with the two extremes of island and mainland existing, but with plenty in between-compare with Hayward's (2012) aquapelagos-depending on the aspects of islandness which are present and to what level.

The absence of a complete dichotomy between island and non-island geographies helps in interpreting and applying vulnerability and resilience as aspects of islandness. Studies of and for island geographies (Gane 1975; McLean et al. 1977; O'Keefe and Conway 1977) provided a significant part of the earlier baseline for understanding vulnerability and resilience for development. Aspects of vulnerability and resilience in development also emerged from academic and practical reaction to the Sahel drought of 1968-1974 (Copans 1975; Cuny 1983; Glantz 1976), especially 
regarding the degree to which human decisions over the long-term, much more than precipitation variations, caused the disaster and the need for humanitarian aid. These externally imposed decisions, such as forcing nomads to settle and superseding traditional agricultural knowledge with recent approaches, created vulnerability and reduced resilience to drought and hence caused the disaster. Changing water use patterns further diminished water availability. Nevertheless, diverse island case studies - from frost in Papua New Guinea's highlands (Waddell 1975) to historical perspectives of Caribbean disasters (Jeffery 1982) —remained at the forefront of interpreting the Sahel's situation in the global context of vulnerability, resilience, and development.

Consequently, islands of vulnerability and resilience show that mechanistic views of the terms-e.g. those often dominating climate change definitions (IPCC 2013-2014) including 'resilience' using the ecological term 'disturbance'-miss the depth and subtleties apparent in island geographies. Calculative, ostensibly objective views of vulnerability and resilience are given significant credence when determining where to allocate development resources and which projects to select for grants. Given the varied definitions and schools of thought, along with some aspects taken for granted without interrogation, vulnerability and resilience are much more subjective, being tinted by cultural, disciplinary, and qualitative lenses. This situation is not detrimental, because interests and needs vary around locations, contexts, and goals. Applying universal vulnerability and resilience formulae helps to compare and contrast, but introduces systematic error through losing intangible, qualitative, subjective aspects which are the meanings of vulnerability and resilience for the people affectedand who often do not relate to these terms.

A focus on quantification yields a manufactured number which is then often embraced without context, nuance, or sometimes even error bars. It represents merely a small snapshot in space and time, being indicative of bounded vulnerability and resilience at the time of the calculation. In contrast, island geographies present vulnerability and resilience as a set of prevailing, ever-present, chronic conditions to be addressed as such (Lewis 1999, 2009). The pervasiveness and relevance of each condition depends on perspective and context. The perennial debate surrounding island geographies about constructing fixed links (Baldacchino 2007) - bridges, tunnels, and causeways (and, in some cases, also interpreted as airports and communication links) - is framed around creating opportunities (resilience) while losing islandness and community (vulnerability). Different viewpoints see the same phenomenon, the fixed link, as either vulnerability or resilience, considering again the discussion above on how the aspects of islandness of boundedness, smallness, and isolation can spawn resilience while noting how fixed links can enhance islandness (Lee et al. 2017). One implication is that some parties might not wish to counter vulnerability or to build resilience, because augmenting vulnerability and diminishing resilience in others does the reverse for themselves, according to their viewpoint.

This story has long been told in disaster research to explain why preventing a disaster is not always a priority for those with the power to do so, even when they inadvertently augment their own vulnerability without realising or accepting it (Hewitt 1983; Lewis 1999; Wisner 1993). For Pacific island geographies, Campbell (2009) describes how many islanders were typically resilient regarding diverse development difficulties, accepting the challenges but with their own ways of dealing with them. Contemporary development interventions often supported by island leaders have not only increased some island vulnerability but also made the islanders view themselves as being vulnerable.

Island geographies also provide perspective on absolute compared to proportional analyses for vulnerability and resilience (Lewis 1999, 2009). Absolute analyses indicate exactly who is affected, through numbers of locations, people, infrastructure, ecosystems, and communities. Proportional analyses describe the proportions or percentages affected. When Mt. Vesuvius in mainland Italy erupted in 1944, the toll was 26 dead and 12,000 displaced from a comparatively small eruption ranked 3/8 on the Volcanic Explosivity Index (Pratt 2016). When the volcano comprising Montserrat, 
a Caribbean island, erupted from 1995-2013, the toll was 19 dead and approximately 12,000 displaced with eruptions not exceeding Volcanic Explosivity Index 3 (GVP 2017; Pattullo 2000).

Given these impacts, the absolute vulnerability and resilience in both locations would seem to be approximately the same. In Italy, the affected population was over one million in Naples alone (Ginsborg 2003) leading to perhaps a $1 \%$ displacement rate and less than a $0.003 \%$ death rate. When Montserrat's volcano started erupting in 1995, the island's population was approximately 12,000 (Pattullo 2000) for a 100\% displacement rate, 100\% of infrastructure destroyed, $100 \%$ of ecosystems altered, and the proportional equivalent of over 1,500 deaths in Naples. Having everyone and everything affected across a $102 \mathrm{~km}^{2}$ island yields a different form of vulnerability than having a tiny fraction affected in a non-island city, even though the city was approximately the same area as Montserrat. Absolute and proportional vulnerability and resilience each have importance for understanding the development context.

Rather than an objective snapshot, both vulnerability and resilience are contextualised. They reveal not just the picture at the place and time in which it was taken, but also how history led to the current state and the possible futures which could result from the current state. Available pathways to move forward are described as are the pathways not available and the states not experienced (which might often be what could have been).

One of the most prominent development illustrations from island geographies is climate change impacts. Many authors presume doomsday scenarios of disappearing islands and mass migrations of climate change refugees (see analysis and critiques by Farbotko 2010 and Kelman 2018). Assessing the current state of empirical evidence for low-lying islands found little support for either disappearance or mass migration under measurable climate change impacts, but also recognised that the worst climate change impacts have yet to be experienced (Kelman 2018).

Lewis $(1989,1990)$ were amongst the first peer-reviewed journal publications linking vulnerability and global environmental change. They used island geographies to highlight the likely challenges of climate change induced sea-level rise as well as responses to and abilities for dealing with these challenges; that is, covering both vulnerability and resilience to climate change impacts from an island perspective. The key for Kelman (2018) and Lewis (1990) was not to complete a top-down quantitative assessment, but instead to understand and evaluate what is and is not known about the past and the present to provide options for the future, without being inhibited in decision-making by the ever-present unknowns and uncertainties. A balance of local and non-local perspectives ensures that multiple perspectives are combined, building up a spatial and temporal analysis balancing breadth and depth of the vulnerability process and the resilience process for low-lying islands facing climate change impacts (amidst wider development topics).

In addition to overcoming stereotypes regarding aspects of islandness, underscoring potential parallels and differences with non-island coastlines experiencing analogous climate change impacts can assist in moving away from manufactured islands of vulnerability and resilience into realistic and practical science, policy, and practice for island geographies implementing development under climate change impacts. Rather than manufacturing vulnerability and resilience to conform to a single, artificial meaning - and thereby islanding it - islandness shows how to localise vulnerability and resilience for acting on development, lessons which are transferable to non-island geographies such as the Sahel or Rio de Janeiro.

\section{Conclusions}

For development topics, many island geographies are showcased as being islands of vulnerability and resilience. Assumptions and top-down labelling often imbue discussions, not being inevitably 
incorrect or misguided, but potentially introducing slants and stereotypes which rarely provide the full picture or full prospects for understanding boundedness, smallness, isolation, and littorality as aspects of islandness. When labels and meanings are manufactured, they can formulate and progress a self-perpetuating agenda for academics and practitioners who choose to use vulnerability and resilience as excuses to do what they want to do anyway, such as cutting aid budgets or devising constructs with limited meaning and use beyond specialists. Yet using the terms sometimes yields advantages in obtaining support from donors expecting the terms to be used, suggesting how vulnerability and resilience have become islands unto themselves. That is, vulnerability and resilience have been made to be bounded and isolated through being viewed as the defining characteristics of islands and islandness rather than as aspects thereof.

Island geographies in their diversities teach that vulnerability and resilience in their diversities, rather than being opposites or independent variables, are inextricably intertwined - supporting, contrasting with, impeding, and boosting each other. Observing vulnerabilities can generate the kick needed to improve. Basking in resilience can stagnate the needed step-change. Within boundedness, smallness, isolation, and littorality as assumed aspects of islandness, vulnerability and resilience are empowering and disempowering for development, in that not all vulnerability is detrimental and not all resilience is positive.

\section{References}

Alexander DE 2013 Resilience and disaster risk reduction: An etymological journey Natural Hazards and Earth System Sciences 13 2707-2716

Anderson R 2016 Islands within an almost island Shima 10 33-47

Baldacchino G ed 2007 Bridging islands: The impact of fixed links Acorn Press, Charlottetown

Baldacchino G ed 2018 The Routledge international handbook of island studies Routledge, Abingdon

Campbell J 2009 Islandness: vulnerability and resilience in Oceania Shima 3 85-97

Castillo-Manzano JI, López-Valpuesta L and Pedregal DJ 2012 How can the effects of the introduction of a new airline on a national airline network be measured? A time series approach for the Ryanair case in Spain Journal of Transport Economics and Policy 46 263-279

Copans J ed 1975 Sécheresses et famines du Sahel F. Maspero, Paris

Cuny F 1983 Disasters and development Oxford University Press, Oxford

Dodds R 2008 Malta's tourism policy: standing still or advancing towards sustainability? Island Studies Journal 2 47-66

Encontre P 1999 The vulnerability and resilience of small island developing states in the context of globalization Natural Resources Forum 23 261-270

Farbotko C 2010 Wishful sinking: disappearing islands, climate refugees and cosmopolitan experimentation Asia Pacific Viewpoint 51 47-60

Gaillard JC 2010 Vulnerability, capacity, and resilience: perspectives for climate and disaster risk reduction Journal of International Development 22 218-232 
Gaillard JC, Clavé E, Vibert O, Azhari D, Denain J-C, Efendi Y, Grancher D, Liamzon CC, Sari DR and Setiawan R 2008 Ethnic groups' response to the 26 December 2004 earthquake and tsunami in Aceh, Indonesia. Natural Hazards 47 17-38

Gane M 1975 Report of a mission to assess the hurricane factor for planning purposes in Fiji University of Bradford, Bradford

Ginsborg P 2003 A history of contemporary Italy: society and politics, 1943-1988 Palgrave Macmillan, New York

Glantz MH ed 1976 The politics of natural disaster: the case of the Sahel drought Praeger, New York

Grydehøj A 2008 Nothing but a shepherd and his dog: social and economic effects of depopulation in Fetlar, Shetland Shima 2 56-72

Grydehøj A 2015 Island city formation and urban island studies Area 47 429-435

Grydehøj A 2017 A future of island studies Island Studies Journal 12 3-16

GVP 2017 Soufrière Hills Global Volcanism https://volcano.si.edu/volcano.cfm?vn=360050 accessed 4 August 2017

Hay P 2006 A phenomenology of islands Island Studies Journal 1 19-42

Hayward P 2012 Aquapelagos and aquapelagic assemblages Shima 6 1-11

Hewitt K ed 1983 Interpretations of Calamity Allen \& Unwin, London

IPCC 2013-2014 Fifth Assessment Report IPCC (Intergovernmental Panel on Climate Change), Geneva

Jeffery SE 1982 The creation of vulnerability to natural disaster: case studies from the Dominican Republic Disasters 6 38-43

Joseph M 2013 Fluid New York: Cosmopolitan Urbanism and the Green Imagination Duke University Press, Durham

Kelman I 2018 Islandness within climate change narratives of small island developing states (SIDS) Island Studies Journal 13 forthcoming

Kendra JM and Wachtendorf T 2016 American Dunkirk: The waterborne evacuation of Manhattan on 9/11 Temple University Press, Philadelphia

Lee SH, Huang WH, Grydehøj A 2017 Relational geography of a border island: local development and compensatory destruction on Lieyu, Taiwan Island Studies Journal 12 97-112

Lei $\mathbf{Z}$ and Papatheodorou A 2010 Measuring the effect of low-cost carriers on regional airports' commercial revenue Research in Transportation Economics 26 37-43 
Leung A, Tanko M, Burke M and Shui CS 2017 Bridges, tunnels, and ferries: connectivity, transport, and the future of Hong Kong's outlying islands Island Studies Journal 12 61-82

Lewis J 1989 Sea-level Rise: Some implications for Tuvalu Ambio 18 458-459

Lewis J 1990 The vulnerability of small island states to sea level rise: the need for holistic strategies Disasters 14 241-248

Lewis J 1999 Development in disaster-prone places: studies of vulnerability, Intermediate Technology Publications, London

Lewis J 2009 An island characteristic: derivative vulnerabilities to indigenous and exogenous hazards Shima 3 3-15

McLean RF, Bayliss-Smith RP, Brookfield M and Campbell JR (editor Brookfield H) 1977 The hurricane hazard: natural disaster and small populations, Island Reports No. 1, the UNESCO/UNFPA Population and Environmental Project in the Eastern Islands of Fiji, Man and the Biosphere Programme Australian National University, Canberra

Oberst A and McElroy JL 2007 Contrasting socio-economic and demographic profiles of two, small island, economic species: MIRAB versus PROFIT/SITE Island Studies Journal 2 163-176

O'Keefe P and Conway C 1977 Natural hazards in the Windward Islands University of Bradford, Bradford

Pattullo P 2000 Fire from the mountain Constable and Robinson, London

Pelling M, Uitto JI 2001 Small island developing states: natural disaster vulnerability and global change Environmental Hazards 3 49-62

Pratt SE 2016 Benchmarks: March 17, 1944: The most recent eruption of Mount Vesuvius Earth https://www.earthmagazine.org/article/benchmarks-march-17-1944-most-recent-eruption-mountvesuvius accessed 31 July 2017

Pugh J 2014 Resilience, complexity and post-liberalism Area 46 313-319

Reid J 2012 The disastrous and politically debased subject of resilience Development Dialogue 58 $67-81$

Silver JJ, Gray NJ, Campbell LM, Fairbanks LW and Gruby RL 2015 Blue economy and competing discourses in international oceans governance The Journal of Environment \& Development 24 135-160

Su MM, Wall G and Wang S 2017 Yujiale fishing tourism and island development in Changshan Archipelago, Changdao, China Island Studies Journal 12 127-142

Su P 2017 The floating community of Muslims in the island city of Guangzhou Island Studies Journal $1283-96$

Terret T 2008 The Albertville Winter Olympics: unexpected legacies - failed expectations for regional economic development The International Journal of the History of Sport 25 1903-1921 
Treadaway J 2007 Dancing, dying, crawling, crying: stories of continuity and change in the Polynesian community of Tikopia IPS Publications, Suva

Tuiloma-Palesoo D 2004 Handout mentality Small Islands Voice Global Forum, Last modified November 16, 2004 http://www.sivglobal.org/?read=82

UN 2014 Report of the third International Conference on Small Island Developing States Apia, Samoa, 1-4 September 2014, A/CONF.223/10 UN (United Nations), New York

UNCLOS 1982 United Nations Convention on the Law of the Sea (UNCLOS) of 10 December 1982 UN (United Nations), New York

UNISDR 2017 Terminology. UNISDR (United Nations International Strategy for Disaster Reduction), Geneva

Wachtendorf T 2000 When disasters defy borders: What we can learn from the Red River flood about transnational disasters Australian Journal of Emergency Management 15 36-41

Waddell E 1975 How the Enga cope with frost: responses to climatic perturbations in the Central Highlands of New Guinea Human Ecology 3 249-273

Wisner B 1993 Disaster vulnerability: scale, power and daily life GeoJournal 30 127-140 